\title{
THE USE OF LIQUID CHROMATOGRAPHY METHOD FOR QUANTITATIVE DETERMINATION OF ACTIVE SUBSTANCES IN ENALAPRIL-H TABLETS
}

\author{
Nataliia Bevz, Artem Myhal, Liudas Ivanauskas, Olga Gorokhova, Vasyl Grynenko, \\ Iryna Zhuravel
}

\begin{abstract}
The aim. Combination therapy is used to treat hypertension. Strengthening the action of the ACE inhibitor enalapril is carried out in combination with the thiazide diuretic hydrochlorothiazide. On the pharmaceutical market, such combined preparations are presented by different manufacturers in various concentrations of the active ingredients of enalapril maleate and hydrochlorothiazide. Development of methods for the quantitative determination of active substances in combined drugs by liquid chromatography is topical.

Materials and methods. Shimadzu Nexera X2 LC-30AD liquid chromatograph equipped with DAD SPD-M20A diode array detector, SIL-30AC autosampler and CTO-20AC column thermostat; analytical balance - UniBloc AUW120D; pH meter - Knick type $911 \mathrm{pH}$; chromatographic column ACE C18, size $250 \mathrm{~mm} \times 4.6 \mathrm{~mm}$, packed with octadecylsilyl silica gel for chromatography with a particle size of $5 \mu \mathrm{m}$.

Results. Based on the results of the work, a method for the quantitative determination of enalapril and hydrochlorothiazide in the presence of HPLC was proposed. The obtained validation characteristics indicate that the method for the quantitative determination of hydrochlorothiazide in Enalapril-H tablets corresponds to the following parameters: correctness, precision, linearity $\left(\Delta_{z}=0.70 \leq \max \Delta_{z}=1.60, \delta=0.22 \leq \max \delta=0.51, a=0.71 \leq \max , a=2.60, r=0.9997 \geq \min \right.$ $r=0.9981)$. In the quantitative determination of enalapril maleate in combined tablets, it was found that correctness, precision, linearity are performed $\left(\Delta_{z}=1.21 \leq \max \Delta_{z}=1.60, \delta=0.24 \leq \max \delta=0.51, a=1.35 \leq \max a=2.60, r=0.9991 \geq \min \right.$ $r=0.9981$ ).
\end{abstract}

Conclusions. The method of quantitative chromatographic determination of enalapril maleate and hydrochlorothiazide in an antihypertensive combination drug has been improved. The proposed parameters of the chromatographic separation of the mixture in comparison with the initial ones contribute to a decrease in the costs of monitoring, a decrease in the volume of harmful emissions and cause an extension of the life of the chromatographic column

Keywords: liquid chromatography, enalapril maleate, hydrochlorothiazide, analytical method validation, quantitative determination

(C) The Author(s) 2021

This is an open access article under the CC BY license (http://creativecommons.org/licenses/by/4.0).

\section{Introduction}

Treatment of hypertension to date, according to protocols approved by the Ministry of Health of Ukraine, is the first line drugs, which include thiazide (thiazidelike) diuretics; calcium channel antagonists (CCB); angiotensin-converting enzyme inhibitors (ACEI); angiotensin receptor antagonists and $\beta$-adrenoceptor blockers [1]. To achieve a greater pharmacological effect in the treatment of hypertension, combination therapy with two or more ACEI drugs is used [2,3].

One of the most common combinations of antihypertensive drugs is a combination of ACEI and thiazide diuretics (most often enalapril and hydrochlorothiazide) $[4,5]$. Such therapy is well tolerated by patients, allows to influence systolic and diastolic pressure. First of all, a clear therapeutic effect is due to the peculiarities of each of the combination drugs: enalapril blocks the conversion of angiotensin I to angiotensin II, which leads to inhibition of renin-angiotensin system activity, decreases noradrenaline release, increases the formation of bradykinin (sodium retention decreases) [6]. The combination of enalapril with hydrochlorothiazide en- hances the hypotensive effect due to the synergism of the two drugs: the diuretic lowers blood pressure, while increasing the level of renin, which, in turn, is acted by ACEI, which has an antihypertensive effect by the above mechanisms [7,8].

The market of combination drugs in Ukraine for the treatment of hypertension is represented by drugs in the form of tablets, which include enalapril maleate and hydrochlorothiazide in different concentrations of active substances $(10 \mathrm{mg} / 12.5 \mathrm{mg}$ or $10 \mathrm{mg} / 25 \mathrm{mg}$, or $20 \mathrm{mg} / 25$ $\mathrm{mg}$ ) and manufactured by different manufacturers (Enalapril-H-Health, Enalapril-HL-Health, Enalapril N-Teva, Enalapril/Hydrochlorothiazide KRKA, Enalapril NPharmex, etc.) $[9,10]$.

Liquid chromatography is widely used to standardize drugs. Quantitative determination of hydrochorothiazide or enalapril maleate in tablets according to the requirements of the US Pharmacopoeia (USP) is performed by HPLC [11, 12].

The aim of the study. The aim of the study was to determine the quantitative content of enalapril maleate and hydrochlorothiazide in combined tablets by liquid 
chromatography with the subsequent implementation of the proposed method for creating a monograph of the State Pharmacopoeia of Ukraine (SPhU).

\section{Planning (methodology) of research}

Widespread use of the combined dosage form, which contains as an API enalapril maleate and hydrochlorothiazide, led researchers to develop methods for quantitative evaluation of active substances. For these purposes, instrumental methods are used, in particular spectrophotometry in the UV region and liquid chromatography, based on the determination of one component of enalapril maleate, taking into account the influence of another - hydrochlorothiazide [13].

To solve this goal it was necessary to study the existing methods of chromatographic separation of enalapril maleate and hydrochlorothiazide [14]. The methods described in the literature allow to determine a mixture of enalapril maleate and hydrochlorothiazide in one sample using one column [15] or to perform the determination in two stages using different parameters of the chromatographic system $[16,17]$.

One of the areas of standardization of multicomponent drugs is the transfer of quality control techniques from monographs that are included in current editions of the United States Pharmacopoeia (USP) or the British Pharmacopoeia (BP) $[11,18]$.

Transfer of the method of quantitative determination of enalapril maleate and hydrochlorothiazide in tablets of combined action, which is described in the US Pharmacopoeia, requires confirmation of the correctness of the method [11] and the planning of experimental studies (Fig. 1). To adapt the method to modern conditions of analysis and complete chromatographic separation of mixtures, it was necessary to address the following issues: to carry out the method of quantification in one or different batches, use one or different chromatographic columns, different ratios and flow rates of mobile phases, different wavelengths of detection, the temperature regime of the column, the particle size of the sorbent of the column, etc. (Fig. 2).

Determination of two or more active substances by liquid chromatography with minor changes requires verification of the method, significant changes in the method of analysis lead to the study of validation characteristics in full (Fig. 1).

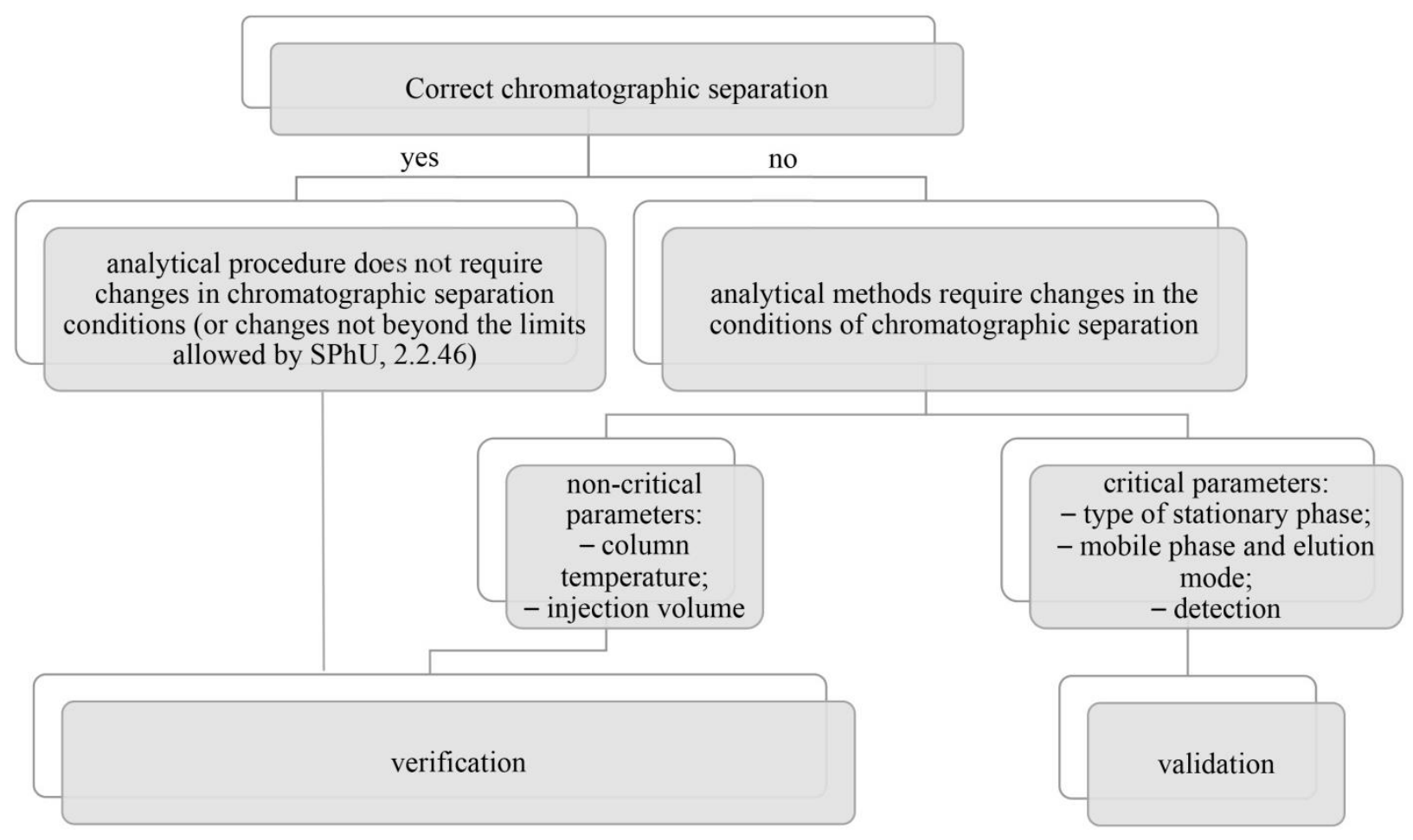

Fig. 1. Planning of experimental researches 


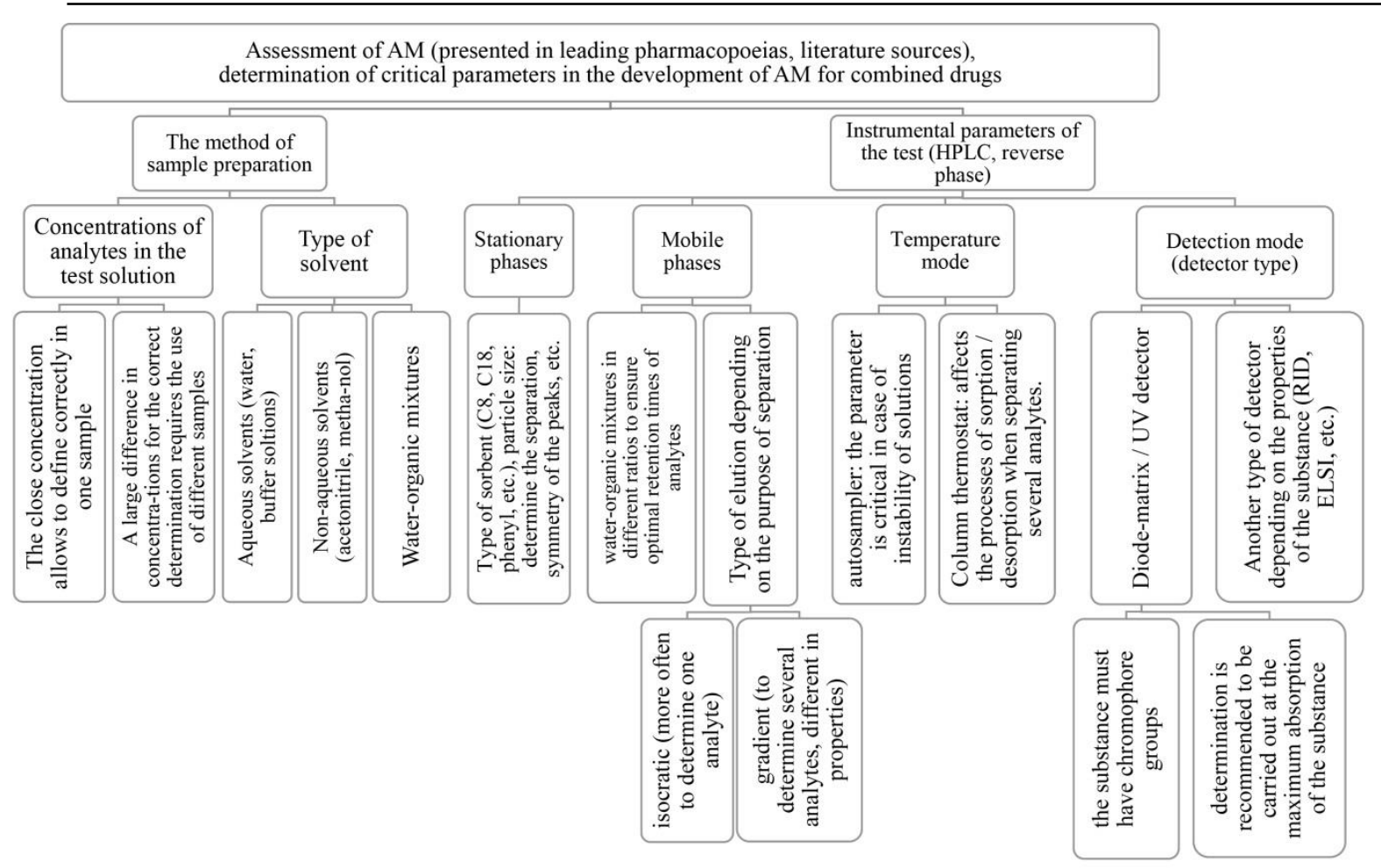

Fig. 2. Stages of the experiment

\section{Materials and methods}

The test used a liquid chromatograph - Shimadzu Nexera X2 LC-30AD, equipped with a diode-matrix detector DAD SPD-M20A, autosampler SIL-30AC and column thermostat CTO-20AC (Shimadzu corp., Japan); analytical scales - UniBloc AUW120D (Shimadzu corp., Japan); pH meter - Knick type 911pH (Knick Elektronische Messgeräte $\mathrm{GmbH} \&$ Co. KG, Germany); column chromatographic ACE C18 size $250 \mathrm{~mm} \times 4.6 \mathrm{~mm}$, filled with silica gel octadecylsilyl for chromatography $\mathrm{P}$ with a particle size of $5 \mu \mathrm{m}$ (Advanced Chromatography Technologies Ltd., UK).

Potassium dihydrogen phosphate $R$, phosphoric acid $R$, methanol $R$, acetonitrile for chromatography $R$ produced by Sigma-Aldrich were used in the studies. Hydrochlorothiazide (certificate of analysis No. 582, Changzhou Pharmaceutical Co. Ltd.) and enalapril maleate (series 3011-1111-236) were used as standard samples.

To test the proposed methods for determining the active substances of hydrochlorothiazide and enalapril maleate in the combined drug used commercial batches of the drug presented on the pharmaceutical market of Ukraine, which were purchased at the pharmacy.

\section{Research methods}

Hydrochlorothiazide. The determination is performed by liquid chromatography (SPhU / EP, 2.2.29, current edition).

Buffer solution. $0.136 \mathrm{~g}$ of potassium dihydrogen phosphate $R$ is dissolved in $800 \mathrm{ml}$ of water $R$, the $\mathrm{pH}$ of the solution is adjusted to $2.0 \pm 0.05$ with phosphoric acid $R$, the volume of the solution is adjusted to the mark with water $R$.

Test solution. About $0.11 \mathrm{~g}$ of tablet powder (equivalent to $5 \mathrm{mg}$ of hydrochlorothiazide), placed in a volumetric flask with a capacity of $50 \mathrm{ml}$, add $12.5 \mathrm{ml}$ of buffer solution, sonicated for 15 minutes, add $12.5 \mathrm{ml}$ of methanol $R$, sonicated for 15 minutes, add $12.5 \mathrm{ml}$ of methanol $R$, sonicated for 15 minutes. The volume of the solution is adjusted to the mark with a buffer solution. Mix thoroughly and filter through a filter with a pore diameter of not more than $0.45 \mu \mathrm{m}$.

Comparison solution. $50 \mathrm{mg}$ of WS or RS hydrochlorothiazide is placed in a volumetric flask with a capacity of $500.0 \mathrm{ml}$, add $125 \mathrm{ml}$ of buffer solution, sonicated for 15 minutes, add $125 \mathrm{ml}$ of methanol $R$, sonicated for 15 minutes. The volume of the solution is adjusted to the mark with a buffer solution. Mix thoroughly and filter through a filter with a pore diameter of not more than $0.22 \mu \mathrm{m}$ (final concentration $0.1 \mathrm{mg} / \mathrm{ml}$ ).

The determination is performed on a liquid chromatograph with a diode-matrix detector under the following conditions:

- column chromatographic size $250 \mathrm{~mm} \times 4.6 \mathrm{~mm}$, filled with silica gel octadecylsilyl for chromatography $\mathrm{R}$ with a particle size of $5 \mu \mathrm{m}$ (for example, ACE C18, or similar, for which the suitability of the chromatographic system);

- mobile phase: acetonitrile for chromatography $\mathrm{R}$ - buffer solution (10:90);

- flow rate $-1.2 \mathrm{ml} / \mathrm{min}$;

- column temperature: $30^{\circ} \mathrm{C}$

- detection at wavelengths of $310 \mathrm{~nm}$;

- chromatography time: 15 minutes.

Chromatograph $50 \mu \mathrm{l}$ of reference solution. ble if:

The chromatographic system is considered suita-

- the efficiency of the column, calculated from the peak of hydrochlorothiazide obtained on the chromato- 
gram of the reference solution, is not less than 1000 theoretical plates;

- the coefficient of symmetry of the peak of hydrochlorothiside obtained on the chromatogram of the reference solution is not less than 2.0 (Table 1);

- the relative standard deviation calculated from the areas of the hydrochlorothiazide peaks obtained from the reference solution for 2 parallel injections should not exceed $0.25 \%$; for 3 - not more than $0.67 \%$; for $4-$ not more than $0.96 \%$; for 5 - no more than $1.19 \%$; for $6-$ no more than $1.38 \%$.

Chromatograph $50 \mu \mathrm{l}$ of the test solution.

Table 1

Release order and relative retention times of peaks for Hydroclorotiazide determination

\begin{tabular}{|c|c|c|}
\hline $\begin{array}{c}\text { Release } \\
\text { order }\end{array}$ & Analyte & $\begin{array}{c}\text { Relative retention } \\
\text { times }\end{array}$ \\
\hline 1 & Maleate & about 0.22 \\
\hline 2 & Enalapril & about 0.3 \\
\hline 3 & Hydrochlorothiazide & 1 \\
\hline
\end{tabular}

The content of hydrochlorothiazide, in milligrams, is calculated by the formula:

$$
X_{i}=\frac{S_{i} \cdot m_{0} \cdot P \cdot 50.0 \cdot m_{a v}}{S_{0} \cdot m_{i} \cdot 100 \cdot 500.0}
$$

where: $S_{i}$ - the average value of the areas of the peaks of hydrochlorothiazide, calculated from the chromatograms of the test solution; $S_{0}$ - the average area of the hydrochlorothiazide peaks calculated from the chromatograms of the reference solution; $m_{i}$ - weight of an aliquot of powder tablets, in milligrams; $m_{0}$-weight of an aliquot of RS or WS hydrochlorothiazide, in milligrams; $P$ - the content of active substance in RS or WS hydrochlorothiazide, in percent; $M_{a v}$ - average tablet weight, in milligrams, determination is performed according to SPhU / EP, 2.9.5, current edition.

The content of hydrochlorothiazide $\left(\mathrm{C}_{7} \mathrm{H}_{8} \mathrm{C}_{1} \mathrm{~N}_{3} \mathrm{O}_{4} \mathrm{~S}_{2}\right)$ in terms of average tablet weight should be from $11.875 \mathrm{mg}$ to $13.125 \mathrm{mg}$.

Enalapril maleate. The determination is carried out by liquid chromatography (SPhU/EP, 2.2.29, current edition).

The buffer solution is prepared as described in "Hydrochlorothiazide".

Test solution. About $0.220 \mathrm{~g}$ of tablet powder (equivalent to $10 \mathrm{mg}$ of enalapril maleate) is placed in a $50.0 \mathrm{ml}$ volumetric flask, $12.5 \mathrm{ml}$ of buffer solution are added, sonicated for 15 minutes, $12.5 \mathrm{ml}$ of methanol $R$ are added, sonicated for 15 minutes. The volume of the solution is adjusted to the mark with a buffer solution. Mix thoroughly and filter through a filter with a pore diameter of not more than $0.45 \mu \mathrm{m}$.

Comparison solution. $50 \mathrm{mg}$ of WS or RS enalapril maleate is placed in a volumetric flask with a capacity of $250.0 \mathrm{ml}$, add $62.5 \mathrm{ml}$ of buffer solution, sonicate for 15 minutes, add $62.5 \mathrm{ml}$ of methanol $R$, sonicate for 15 minutes The volume of the solution is adjusted to the mark with a buffer solution. Mix thoroughly and filter through a filter with a pore diameter of not more than $0.45 \mu \mathrm{m}$ (final concentration $0.2 \mathrm{mg} / \mathrm{ml}$ ).

The determination is performed on a liquid chromatograph with a diode-matrix detector under the following conditions:

- column chromatographic size $250 \mathrm{~mm} \times 4.6 \mathrm{~mm}$, filled with silica gel octadecylsilyl for chromatography $\mathrm{R}$ with a particle size of $5 \mu \mathrm{m}$ (for example, ACE C18, or similar, for which the suitability of the chromatographic system);

- mobile phase: acetonitrile for chromatography $\mathrm{R}$ buffer solution (40: 60);

- flow rate $-1.5 \mathrm{ml} / \mathrm{min}$;

- column temperature: $50{ }^{\circ} \mathrm{C}$;

- detection at a wavelength of $215 \mathrm{~nm}$;

- chromatography time: 10 minutes.

Chromatograph $50 \mu$ of reference solution.

The chromatographic system is considered suitable if:

- the efficiency of the column, calculated for the peak of enalapril obtained on the chromatogram of the reference solution, is not less than 700 theoretical plates;

- the symmetry coefficient of the peak enalapril obtained on the chromatogram of the reference solution is not less than 3.5 (Tab. 2);

- the relative standard deviation calculated from the areas of enalapril peaks obtained from the reference solution for 2 parallel injections should not exceed $0.25 \%$; for 3 - not more than $0.67 \%$; for 4 - not more than $0.96 \%$; for 5 - no more than $1.19 \%$; for 6 - no more than $1.38 \%$.

Chromatograph $50 \mu$ of the test solution.

Table 2

Release order and relative retention times of peaks for Enalapril determination

\begin{tabular}{|c|c|c|}
\hline $\begin{array}{c}\text { Release } \\
\text { order }\end{array}$ & Analyte & $\begin{array}{c}\text { Relative retention } \\
\text { times }\end{array}$ \\
\hline 1 & Maleate & about 0.57 \\
\hline 2 & Hydrochlorothiazide & about 0.75 \\
\hline 3 & Enalapril & 1 \\
\hline
\end{tabular}

The content of enalapril maleate, in milligrams, is calculated by the formula:

$$
X_{i}=\frac{S_{i} \cdot m_{0} \cdot P \cdot 50.0 \cdot m_{a v}}{S_{0} \cdot m_{i} \cdot 100 \cdot 250.0}
$$

where $S_{i}$ - the average value of the peak areas of enalapril, calculated from the chromatograms of the test solution; $S_{0}$ - the average value of the peak areas of enalapril, calculated from the chromatograms of the reference solution; $m_{i}$ - weight of an aliquot of powder tablets, in milligrams; $m_{0}-$ weight of a aliquot of RS or WS enalapril maleate, in milligrams; $P$ - the content of active substance in RS or WS enalapril maleate, in percent; $\mathrm{M}_{\mathrm{av}}$. - average weight of tablets, in milligrams, determination is carried out according to SPhU/EP, 2.9.5, current edition. 
The content of enalapril maleate $\left(\mathrm{C}_{24} \mathrm{H}_{32} \mathrm{~N}_{2} \mathrm{O}_{9}\right)$ in terms of the average weight of the tablet should be from $4.75 \mathrm{mg}$ to $5.25 \mathrm{mg}$.

The following solutions were additionally prepared for validation/verification of analytical methods:

Control solution: place $12.5 \mathrm{ml}$ of methanol $R$ in a $50.0 \mathrm{ml}$ volumetric flask and make up to the mark with buffer solution.

Model solutions (hydrochlorothiazide). Place $20 \mathrm{mg}$ of RS or WS hydrochlorothiazide in a $50.0 \mathrm{ml}$ volumetric flask, add $12.5 \mathrm{ml}$ of buffer solution and sonicate for 15 minutes, add $12.5 \mathrm{ml}$ of methanol $R$ and keep in an ultrasonic bath for 15 minutes. The volume of the solution is adjusted to the mark with a buffer solution.
Place the volume of the aliquot of the resulting solution shown in Tab. 1 in a $20.0 \mathrm{ml}$ volumetric flask and make up to the mark with buffer solution.

Model solutions (enalapril maleate). Place $40 \mathrm{mg}$ of RS or WS enalapril maleate in a $50.0 \mathrm{ml}$ volumetric flask, add $12.5 \mathrm{ml}$ of buffer solution and sonicate for 15 minutes, add $12.5 \mathrm{ml}$ of methanol $R$ and keep in an ultrasonic bath for 15 minutes. The volume of the solution is adjusted to the mark with a buffer solution. The volume of the aliquot of the resulting solution shown in Table 3 is placed in a $20.0 \mathrm{ml}$ volumetric flask and made up to the mark with buffer solution. Appropriate $100 \%$ model solutions were used as reference solutions.

Table 3

Calculation of dilutions to determine linearity

\begin{tabular}{|c|c|c|c|c|}
\hline Model solution & Concentration level & An aliquot & $\begin{array}{c}\text { Concentration, mg/ml } \\
\text { Enalapril maleate }\end{array}$ & $\begin{array}{c}\text { Concentration, mg/ml } \\
\text { Hydrochlorothiazide }\end{array}$ \\
\hline L1 & $80 \%$ & $4.00 \mathrm{ml}$ & 0.16 & 0.080 \\
\hline L2 & $85 \%$ & $4.25 \mathrm{ml}$ & 0.17 & 0.085 \\
\hline L3 & $90 \%$ & $4.50 \mathrm{ml}$ & 0.18 & 0.090 \\
\hline L4 & $95 \%$ & $4.75 \mathrm{ml}$ & 0.19 & 0.095 \\
\hline L5 & $100 \%$ & $5.00 \mathrm{ml}$ & 0.20 & 0.100 \\
\hline L6 & $105 \%$ & $5.25 \mathrm{ml}$ & 0.21 & 0.110 \\
\hline L8 & $110 \%$ & $5.50 \mathrm{ml}$ & 0.22 & 0.115 \\
\hline L9 & $115 \%$ & $5.75 \mathrm{ml}$ & 0.23 & 0.120 \\
\hline RS & $120 \%$ & $6.00 \mathrm{ml}$ & 0.24 & 0.100 \\
\hline
\end{tabular}

\section{Research results}

For the quantification of enalapril maleate in the combined medicinal product in the presence of hydrochlorothiazide in combination with the method, the method of chromatographic separation was chosen, namely liquid chromatography with spectrophotometric detection (SPhU/EP, 2.2.29, current edition), which has the ability to separate the retention time of the target peak of enalapril from interfering peaks of substances [18].

The method of determination of enalapril maleate and hydrochlorothiazide in the combined medicinal product according to the monograph USP 39 "Enalapril maleate and Hydrochlorothiazide Tablets" was taken as a basis, according to which the tests were done at wavelengths of $210 \mathrm{~nm}$ (for enalapril maleate) and $310 \mathrm{~nm}$ (for hydrochlorothiazide).

The procedure regulates the chromatographic separation of enalapril maleate on the sorbent at a temperature of $65^{\circ} \mathrm{C}$, but the limiting parameters of the chromatographic column are not more than $60{ }^{\circ} \mathrm{C}$. The use of a chromatographic column above the requirements of the operating parameters leads to the cleavage of the grafted stationary phase, the loss of the resolution of the chromatographic column, which will indicate the failure of the column. In order to extend the service life of the column, the temperature of the thermostat was reduced to $50{ }^{\circ} \mathrm{C}$.

$\mathrm{SPhU} / \mathrm{EP}, 2.2 .46$, the current edition, allows minor changes in the parameters of the method to achieve the suitability of the chromatographic system, but the proposed changes go beyond the permitted limits. Since changes in temperature are uncritical, it is sufficient to verify the method.

Determination of hydrochlorothiazide in a combination drug in the combined presence of enalapril maleate was based on the method presented in the monograph USP 39 "Enalapril maleate and Hydrochlorothiazide Tablets", with a number of modifications. In order to unify the conditions for the determination of hydrochlorothiazide, a chromatographic column with similar characteristics as for the determination of enalapril maleate was selected.

Reducing the flow of the mobile phase compared to the original method from $2.5 \mathrm{ml} / \mathrm{min}$ to $1.2 \mathrm{ml} / \mathrm{min}$ leads to a decrease in pressure in the system and, thus, to a reduction of the damaging effect on the stationary phase.

Along with the extension of the service life of the chromatographic column while maintaining the efficiency of the chromatographic system and the appropriate parameters of the chromatographic separation. The proposed changes can help reduce the cost of control, reduce emissions by lower costs of mobile phases.

The change in temperature during the transfer of the existing method requires verification of the method of quantitative determination of enalapril maleate in the combined drug in the joint presence of the target analysis with hydrochlorothiazide and the study of the following parameters: suitability of the chromatographic system; specificity; linearity in the range of application of the technique; correctness and precision. 
The total uncertainty of the method was evaluated in accordance with the requirements of SPhU [20] and found that the uncertainty of the method is $0.49 \%$ and is insignificant because the inequality is maintained: $0.49 \% \leq \max \Delta_{\mathrm{AS}}=0.51 \%$. It was found that the suitability of the chromatographic system is maintained (Table. 4).

To confirm the specificity of the analytical method, the absence of interfering peaks was determined on the chromatograms of the control solution, the comparison solution of hydrochlorothiazide and the test solution, the retention times of which coincide with the retention times of the main peak of enalapril (Fig. 3-6).

To assess the linearity, the model solutions L1-L9 (Table 3) were analyzed in the chromatographic conditions specified by the method. At least two parallel chromatograms were obtained for each solution, and the average value of the peak areas was calculated to evaluate the results. Evaluation of linearity parameters was performed in normalized coordinates in accordance with the requirements of SPhU (Table 5, Fig. 7).

Suitability of the chromatographic system for enalapril determination method

\begin{tabular}{|c|c|c|c|}
\hline Parameter & Result & Criterion & Conclusions \\
\hline Column efficiency & 1725 & Not less than 700 t. p. & Corresponds \\
\hline Symmetry of enalapril peak & 1.27 & No more than 3.5 & Corresponds \\
\hline RSD, \% & 0.13 & for 3- no more than $0.67 \%$ & Corresponds \\
\hline
\end{tabular}

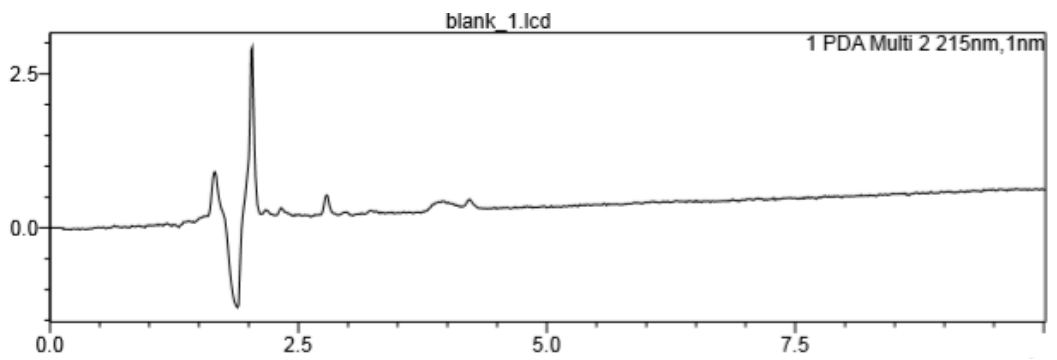

Fig. 3. Chromatogram of the control solution

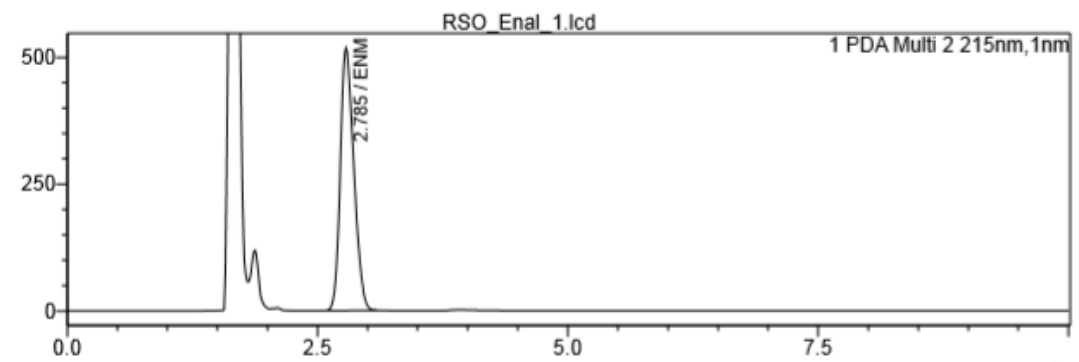

Fig. 4. Chromatogram of enalapril maleate comparison solution

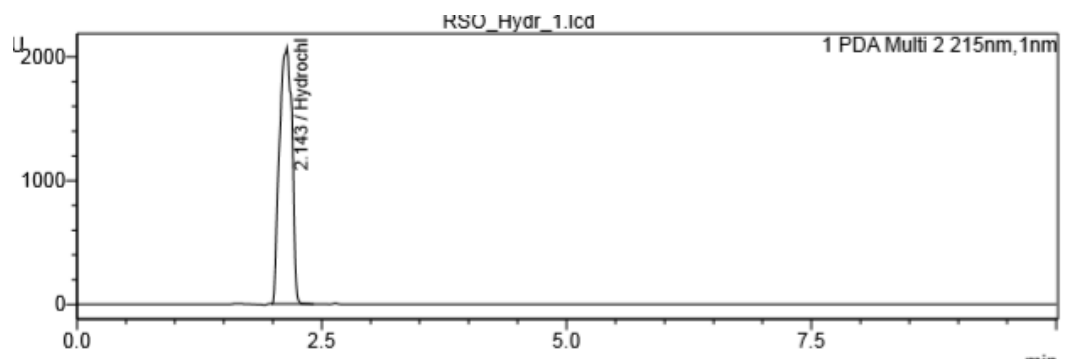

Fig. 5. Chromatogram of hydrochlorothiazide comparison solution

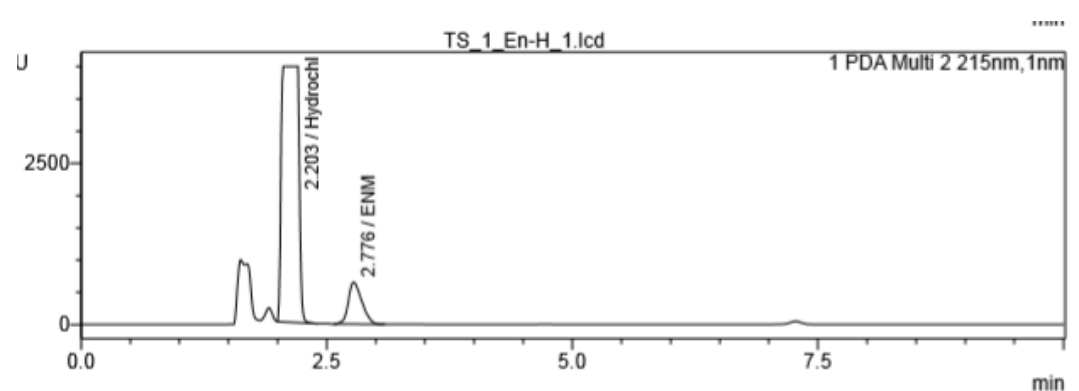

Fig. 6. Chromatogram of the test solution 
The results of determining the parameters of linearity, correctness and convergence of the analytical method for the determination of enalapril maleate

\begin{tabular}{|c|c|c|c|}
\hline Parameter & Value & $\begin{array}{c}\text { Criterion } \\
\text { (for tolerances } 95-105 \%), \mathrm{n}=9\end{array}$ & Conclusions \\
\hline \multicolumn{4}{|c|}{ Linearity } \\
\hline$b$ & 0.9887 & - & - \\
\hline$S_{b}$ & 0.0159 & - & - \\
\hline$a$ & 1.3516 & $\begin{array}{c}\text { 1) } \leq 1.8946 \cdot s_{a}=3.0389 \\
\text { 2) if not performed } 1) \text {, then } \leq 2.6\end{array}$ & Corresponds \\
\hline$S_{a}$ & 1.6040 & - & - \\
\hline$S_{o}$ & 0.6161 & $\leq \max S_{0}=0.84 \%$ & Corresponds \\
\hline$r$ & 0.9991 & $\geq 0.998$ & Corresponds \\
\hline \multicolumn{4}{|c|}{ Correctness } \\
\hline average $\mathrm{Z} \%$ & 100.24 & - & - \\
\hline systematic error, $\delta \%$ & 0.24 & $\begin{array}{c}1) \leq 0.40 ; \\
\text { 2) if not performed 1), then } \\
\leq \max \delta \%=0.51\end{array}$ & Corresponds \\
\hline \multicolumn{4}{|c|}{ Precision } \\
\hline relative standard deviation, $\mathrm{Sz} \%$ & 0.6484 & - & - \\
\hline relative confidence interval $\Delta \mathrm{z} \%=\mathrm{t}(95 \%, 8) * \mathrm{Sz}$ & 1.2057 & $\leq \max \Delta a s, \%=1.60$ & Corresponds \\
\hline
\end{tabular}

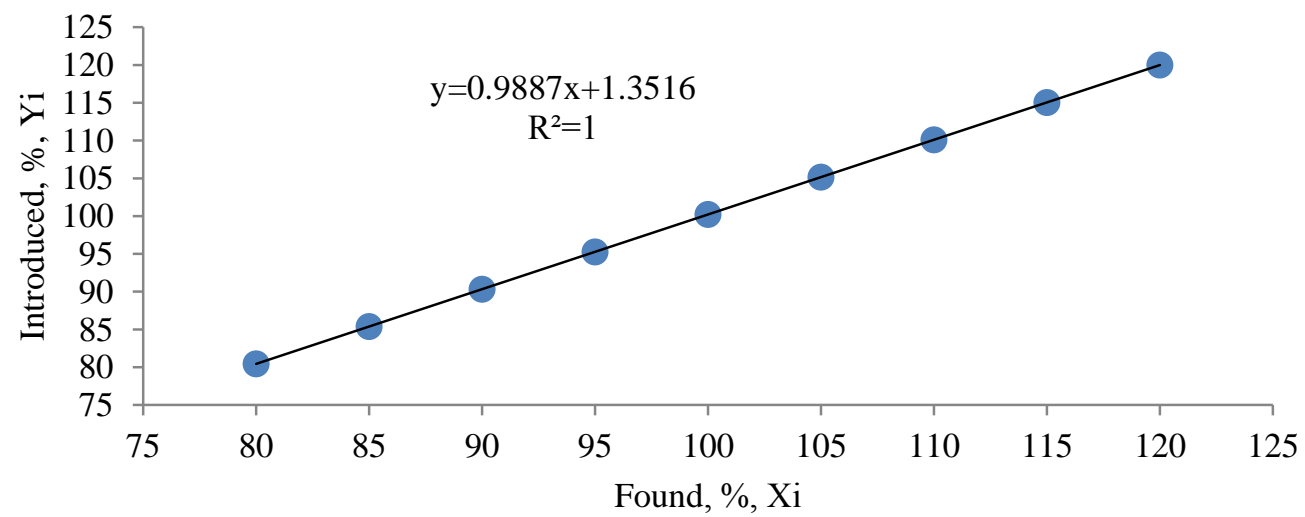

Fig. 7. Graph of the dependence of the analytical signal on the concentration of the model solution Enalapril

The technique is characterized by linearity, accuracy and precision and can be used to quantify enalapril maleate in a combined dosage form.

Research of validation parameters for Hydrochlorothiazide assay method. Confirmation of the possibility of using analytical methods to determine the quantitative content of hydrochlorothiazide requires the study of validation characteristics in full.

Initially, the stability of the solutions over time and the resistance of the analytical procedure to minor changes in accordance with SPhU/EP were determined. The stability of the solutions was studied for 48 hours.

The "found/introduced" ratio was calculated by the formula:

$$
S t, \%=\frac{S_{t, i}}{S_{0}} \cdot 100 \% \text {; }
$$

where $S_{i, t}$, the area of hydrochlorothiazide, calculated from the chromatogram of the i-th solution, analyzed after a certain period of time; $S_{i, 0}-$ the area of hydrochlo- rothiazide, calculated from the chromatogram of the i-th solution analyzed at the beginning of the study.

The results obtained at these intervals were compared with the test results at 0 point. The solutions are stable for 48 hours, as the deviation from $100 \%$ of the ratio "found/introduced" is insignificant and is not more than $\max \Delta_{\mathrm{AS}} 0.51 \%$ (Table 6).

To study the resistance of the analytical method to minor changes, possible changes in the chromatographic system were modelled in accordance with the requirements of the SPhU/EP, 2.2.46. To evaluate this parameter under changed conditions, comparison solutions were chromatographed and the suitability of the chromatographic system was determined [21, 22]. bustness:

Parameters that changed during the study of ro-

1) the flow rate of the mobile phase: $\pm 10 \%$ or $0.1 \mathrm{ml} / \mathrm{min}$;

2) change in the amount of the minor component of the mobile phase (acetonitrile for chromatography R) by $2 \%$ in absolute units; 
3) changes in the temperature of the chromatographic column $\pm 5^{\circ} \mathrm{C}$.

The results of determining the suitability of the chromatographic system under changed conditions are presented in Table 7.

Based on the obtained values (Table 7), it can be concluded that the method is resistant to minor changes in chromatographic parameters, and can be used to quantify hydrochlorothiazide.

The total uncertainty of the method was estimated in accordance with the requirements of SPhU [20, 22] and found that the uncertainty of the method is $0.48 \%$ and is insignificant, because the inequality is maintained: $0.48 \% \leq \max \Delta_{\mathrm{AS}}=0.51 \%$. It was found that the suitability of the chromatographic system is maintained (Table 8).

To confirm the specificity of the analytical method, the absence of interfering peaks was determined on the chromatograms of the control solution, enalapril maleate comparison solution and test solution, the retention times of which would coincide with the retention times of the main hydrochlorothiazide peak (Fig. 8-11).

Table 6

The results of the study of the stability of the test solution and the comparison solution

\begin{tabular}{|c|c|c|c|c|c|c|}
\hline \multicolumn{7}{|c|}{ Comparison solution } \\
\hline Parameter & $0 \mathrm{~h}$ & $1 \mathrm{~h}$ & $4 \mathrm{~h}$ & $8 \mathrm{~h}$ & $24 \mathrm{~h}$ & $48 \mathrm{~h}$ \\
\hline Area & 2531623 & 2534902 & 2534692 & 2533865 & 2527223 & 2533819 \\
\hline Found / entered & - & 100.13 & 100.12 & 100.09 & 99.83 & 100.09 \\
\hline Deviation from $100 \%$ & - & 0.13 & 0.12 & 0.09 & 0.17 & 0.09 \\
\hline Criterion & \multicolumn{6}{|c|}{0.51} \\
\hline \multicolumn{7}{|c|}{ Test solution } \\
\hline Parameter & $0 \mathrm{~h}$ & $1 \mathrm{~h}$ & $4 \mathrm{~h}$ & $8 \mathrm{~h}$ & $24 \mathrm{~h}$ & $48 \mathrm{~h}$ \\
\hline Area & 2536150 & 2535397 & 2536700 & 2536005 & 2536095 & 2536804 \\
\hline Found / entered & - & 99.97 & 100.02 & 99.99 & 100.00 & 100.03 \\
\hline Deviation from $100 \%$ & - & 0.03 & 0.02 & 0.01 & 0.00 & 0.03 \\
\hline Criterion & \multicolumn{6}{|c|}{0.51} \\
\hline
\end{tabular}

Table 7

The results of the study of the resistance of the method to minor changes in the determination of hydrochlorothiazide

\begin{tabular}{|l|c|c|c|c|}
\hline \multirow{2}{*}{ Parameter } & $\begin{array}{c}\text { Retention time of } \\
\text { hydrochlorothiazide } \\
\text { peak, min }\end{array}$ & Column efficiency & $\begin{array}{c}\text { Symmetry of hydrochlo- } \\
\text { rothiazide peak }\end{array}$ & \multirow{2}{*}{ Conclusion } \\
\cline { 3 - 5 } & 10.400 & Not less than 1000 & Not more than 2.0 & \\
\hline Initial conditions & 11.302 & 12530 & 1.027 & Corresponds \\
\hline The flow rate is $1.1 \mathrm{ml} / \mathrm{min}$ & 9.652 & 12774 & 1.044 & Corresponds \\
\hline The flow rate is $1.3 \mathrm{ml} / \mathrm{min}$ & 10.257 & 11586 & 1.064 & Corresponds \\
\hline $\begin{array}{l}\text { The composition of the } \\
\text { mobile phase }+2 \% \text { abs. }\end{array}$ & 10.703 & 11687 & 1.087 & Corresponds \\
\hline $\begin{array}{l}\text { The composition of the } \\
\text { mobile phase }-2 \% \text { abs. }\end{array}$ & 11.948 & 11367 & 1.086 & Corresponds \\
\hline Column temperature $25^{\circ} \mathrm{C}$ & 9.178 & 12193 & 1.079 & Corresponds \\
\hline Column temperature $35^{\circ} \mathrm{C}$ & & & 1.063 & Corresponds \\
\hline
\end{tabular}

Suitability of the chromatographic system

\begin{tabular}{|l|c|c|c|}
\hline \multicolumn{1}{|c|}{ Parameter } & Value & Criterion & Conclusion \\
\hline Column efficiency & 11497 & Not less than 1000 t. p. & Corresponds \\
\hline Symmetry of hydrochlorothiazide peak & 1.1 & No more than 2.0 & Corresponds \\
\hline RSD, \% & 0.013 & for 5 injections - no more than 1.19\% & Corresponds \\
\hline
\end{tabular}

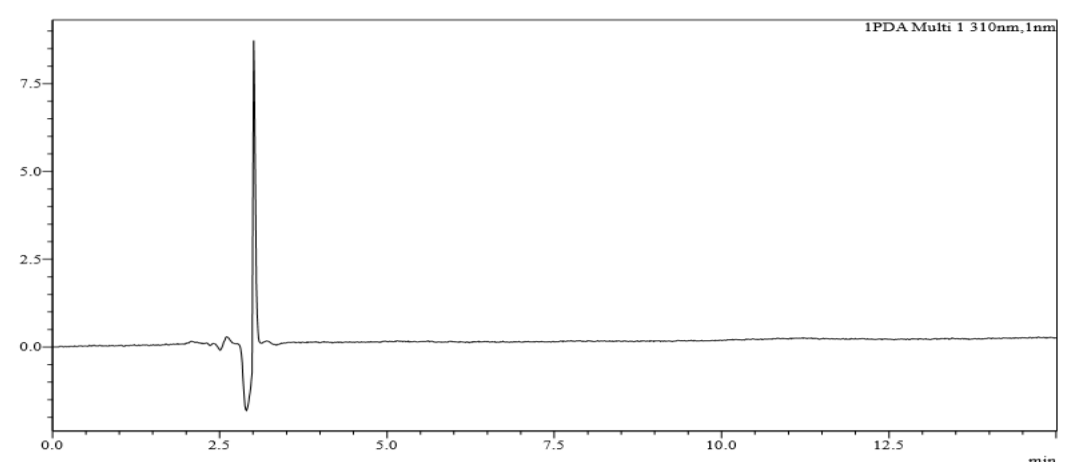

Fig. 8. Chromatogram of the control solution 


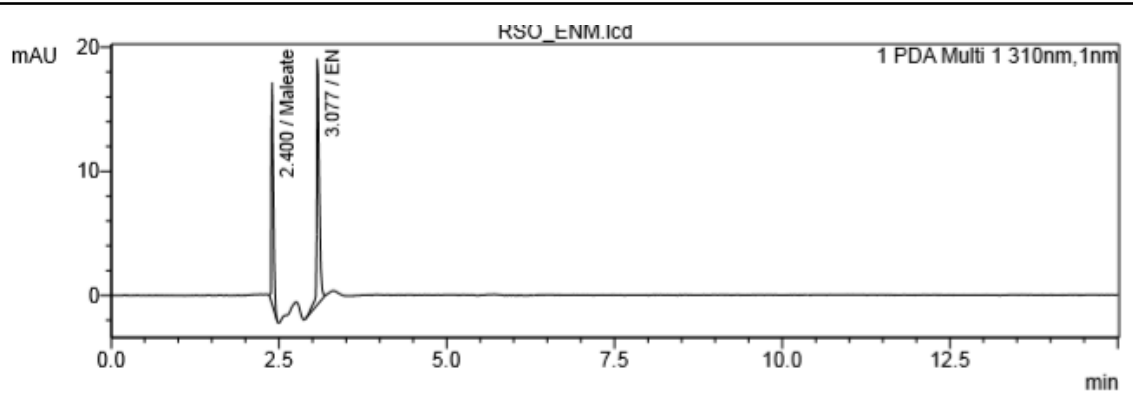

Fig. 9. Chromatogram of enalapril maleate comparison solution

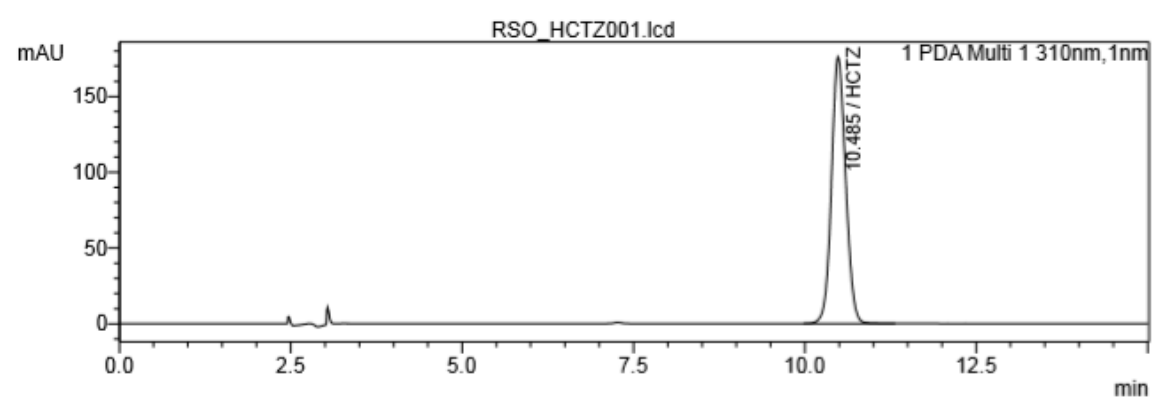

Fig. 10. Chromatogram of hydrochlorothiazide comparison solution

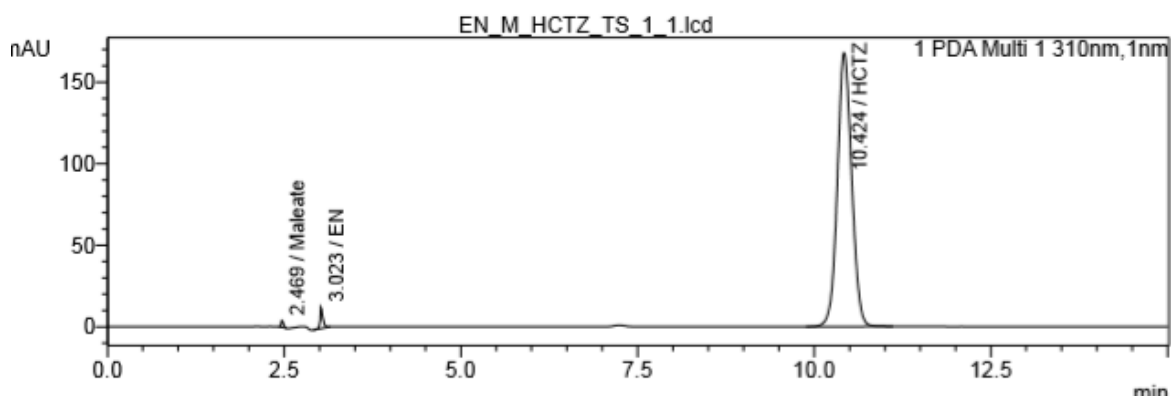

Fig. 11. Chromatogram of the test solution

To assess the linearity, model solutions L1-L9 were analyzed (Table 3 ). Three parallel chromatograms were obtained for each solution, and the mean peak areas were calculated to evaluate the results. The evaluation of linearity parameters was performed in normalized coor- dinates in accordance with the requirements of $\mathrm{SPhU}$. The results of the study of the parameters of linearity, accuracy, convergence of the results of quantitative determination of hydrochlorothiazide are presented in Table 9 and in Fig. 12.

Table 9

The results of determining the parameters of linearity, accuracy and convergence of the method of quantitative determination of hydrochlorothiazide

\begin{tabular}{|c|c|c|c|}
\hline Parameter & Value & Criterion (for tolerances of $95-105 \%$ ), $\mathrm{n}=9$ & Conclusion \\
\hline \multicolumn{4}{|c|}{ Linearity } \\
\hline$b$ & 1.0094 & - & - \\
\hline$S_{b}$ & 0.0089 & - & - \\
\hline$a$ & 0.7119 & $\begin{array}{c}\text { 1) } \leq 1.8946 \cdot s_{a}=1.7067 \\
\text { 2) if not performed } 1 \text { ), then } \leq 2.6\end{array}$ & Corresponds \\
\hline$S_{a}$ & 0.9008 & - & - \\
\hline$S_{o}$ & 0.3460 & $\leq \max S_{0}=0.84 \%$ & Corresponds \\
\hline$r$ & 0.9997 & $\geq 0.9981$ & Corresponds \\
\hline \multicolumn{4}{|c|}{ Accuracy } \\
\hline average $\mathrm{Z} \%$ & 100.22 & - & - \\
\hline systematic error, $\delta \%$ & 0,22 & $\begin{array}{l}1) \leq 0.23 \text {; } \\
\text { 2) if not performed } 1) \text {, then } \leq \max \delta \%=0.51\end{array}$ & Corresponds \\
\hline \multicolumn{4}{|c|}{ Convergence } \\
\hline relative standard deviation, $\mathrm{Sz} \%$ & 0.3741 & - & - \\
\hline $\begin{array}{c}\text { relative confidence interval } \\
\Delta \mathrm{z} \%=\mathrm{t}(95 \%, 8) * \mathrm{Sz}\end{array}$ & 0.6956 & $\leq \max \Delta a s, \%=1.60$ & Corresponds \\
\hline
\end{tabular}




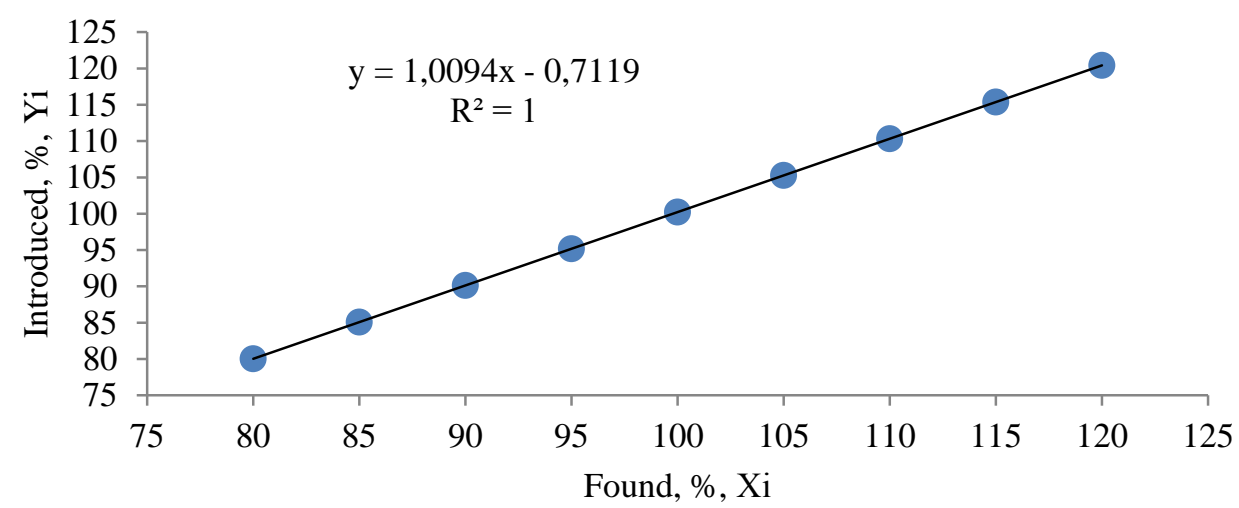

Fig. 12. Graph of the dependence of the analytical signal on the concentration of the model solution of hydrochlorothiazide

Therefore, the method is characterized by linearity, accuracy and convergence and can be used to quantify hydrochlorothiazide in the presence of enalapril maleate.

The proposed methods were tested on three batches of the combined drug Enalapril-H, which contains as active substances hydrochlorothiazide and enalapril ma- leate. The results of the determination of enalapril maleate are presented in Table 10, and hydrochlorothiazide in Table 11.

The quantitative content of enalapril maleate tablets Enalapril-H meet the requirements of the specification.

Quantitative determination of enalapril maleate in tablets Enalapril-H

\begin{tabular}{|c|c|c|c|c|}
\hline \multirow{2}{*}{ Parameter } & \multirow{2}{*}{ Comparison solution } & \multicolumn{3}{|c|}{ Test solution } \\
\hline & & series 1 & series 2 & series 3 \\
\hline $\mathrm{S}_{\mathrm{av}}$ & 6066811 & 6234893 & 6055491 & 6122115 \\
\hline $\mathrm{SD}$ & 156 & 2192 & 290 & 396 \\
\hline RSD, \% & 0.003 & 0.035 & 0.005 & 0.006 \\
\hline Assay & - & 5.056 & 4.957 & 4.980 \\
\hline Assay, av. & - & \multicolumn{3}{|c|}{4.998} \\
\hline aliquot, $\mathrm{mg}=$ & 49.1 & 220 & 217.94 & 219.32 \\
\hline $\mathrm{P}, \%=$ & 100 & & & \\
\hline $\mathrm{m}_{\mathrm{av}}, \mathrm{mg}=$ & 220.43 & & & \\
\hline \multicolumn{5}{|c|}{ Suitability of the chromatographic system } \\
\hline \multicolumn{2}{|c|}{ Parameter } & Value & Criterion & Conclusion \\
\hline \multicolumn{2}{|c|}{ Column efficiency } & 1725 & Not less than 700 t. p. & Corresponds \\
\hline \multicolumn{2}{|c|}{ Symmetry of enalapril peak } & 1.262 & Not more than 3.5 & Corresponds \\
\hline \multicolumn{2}{|c|}{ RSD, $\%$} & 0.003 & for $2-$ not more than $0.25 \%$ & Corresponds \\
\hline
\end{tabular}

Table 11

Quantitative determination of hydrochlorothiazide in Enalapril-H tablets

\begin{tabular}{|c|c|c|c|c|}
\hline \multirow{2}{*}{ Parameter } & \multirow{2}{*}{ Comparison solution } & \multicolumn{3}{|c|}{ Test solution } \\
\hline & & series 1 & series 2 & series 3 \\
\hline $\mathrm{S}_{\mathrm{av}}$ & 2243742 & 2697643 & 2701505 & 2701655 \\
\hline $\mathrm{SD}$ & 1184 & 1020 & 462 & 1235 \\
\hline $\mathrm{RSD}, \%$ & 0.053 & 0.038 & 0.017 & 0.046 \\
\hline Assay & - & 12.386 & 12.290 & 12.295 \\
\hline Assay, av. & - & \multicolumn{3}{|c|}{12.324} \\
\hline aliquot, $\mathrm{mg}=$ & 50.8 & 108.7 & 109.7 & 109.66 \\
\hline $\mathrm{P}, \%=$ & 100 & \multirow{2}{*}{ 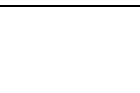 } & \multirow{2}{*}{\multicolumn{2}{|c|}{ (n) }} \\
\hline $\mathrm{m}_{\mathrm{av}}, \mathrm{mg}=$ & 220.43 & & & \\
\hline
\end{tabular}

Suitability of the chromatographic system

\begin{tabular}{|c|c|c|c|}
\hline Parameter & Value & Criterion & Conclusion \\
\hline Column efficiency & 8665 & Not less than 1000 t. p. & Corresponds \\
\hline Symmetry of hydrochlorothiazide peak & 1.037 & Not more than 2.0 & Corresponds \\
\hline RSD, \% & 0.053 & for 3 - not more than 0.67 \%; & Corresponds \\
\hline
\end{tabular}


The quantitative content of hydrochlorothiazide Enalapril-H meet the requirements of the specification.

\section{Discussion of research results}

When adapting the proposed existing chromatographic method for the quantification of enalapril maleate in the combined drug, it is proposed to change the temperature (column temperature $50{ }^{\circ} \mathrm{C}$ ), previous studies were performed at $65^{\circ} \mathrm{C}[11,15]$.

To unify the quantification of hydrochlorothiazide in the combination drug, a chromatographic system with similar parameters as for the determination of enalapril maleate was selected. The procedure was modified according to the following parameters: change of sample preparation conditions, use of one chromatographic column for determination of two substances (column of chromatographic size $250 \mathrm{~mm} \times 4.6 \mathrm{~mm}$, which is used for quantitative determination of enalapril maleate) and reduction of flow rate to $1.2 \mathrm{ml} / \mathrm{min}$. According to the US Pharmacopoeia monograph, determinations were performed using different columns and the mobile phase velocity was $2.5 \mathrm{ml} / \mathrm{min}$ [11]. Improving the methodology reduces the time and cost of control, reducing harmful emissions by reducing the volume of mobile phases, while increasing the sensitivity of the method and the ability to determine the combination in different proportions. The proposed changes required full validation.

Both methods are quite specific, enalapril and hydrochlorothiazide analytes do not affect the determination of each other. During the verification of the methodology, the studied validation characteristics of linearity, correctness and convergence indicate the correctness of the proposed changes.

The method of quantitative determination of hydrochlorothiazide is characterized by linearity, accuracy and convergence of results, resistant to minor changes in chromatographic conditions. The stability of the test solution and the comparison solution was proved within 48 hours. Uncertainty of sample preparation and general uncertainty of the method is insignificant.

Approbation of analytical methods on three commercial batches of the combined drug confirms the reproducibility of the method and the correctness of the obtained results.

Study limitations. The proposed methods for the quantification of enalapril maleate and hydrochlorothiazide in combination have not been studied to determine API data in the presence of other drugs.

Prospects for further research. The proposed conditions for the quantification of hydrochlorothiazide will be used for the analysis of combination drugs from the group of angiotensin-converting enzyme inhibitors.

\section{Conclusions}

It is proposed to improve the method of quantitative determination of enalapril maleate and hydrochlorothiazide in combined tablets in different portions by liquid chromatography. The parameters of the chromatographic separation techniques in comparison with the original methods help to reduce the cost of control, reduce the amount of harmful emissions and increase the life of the chromatographic column. The studied validation characteristics confirm the possibility of using the proposed technique for pharmaceutical analysis of antihypertensive combination drug.

\section{Conflict of interests}

The authors declare that they have no conflicts of interest.

\section{References}

1. Unifikovanyi klinichnyi protokol pervynnoi, ekstrenoi ta vtorynnoi (spetsializovanoi) medychnoi dopomohy. Arterialna hipertenziia. (2012). Zatverdzheno Nakaz Ministerstva okhorony zdorovia. No. 384. 24.05.2012. Available at: https://www.dec.gov.ua/wpcontent/uploads/2019/11/384_2012ykpmd_ag.pdf

2. Tsioufis, C., Dimitriadis, K., Mantzouranis, E., Mani, I., Tousoulis, D. (2016). Differential effects of lercanidipine/enalapril versus amlodipine/enalapril and hydrochlorothiazide/enalapril on target organ damage and sympathetic activation in non-obese essential hypertensive subjects. Current Medical Research and Opinion, 32 (2), 35-41. doi: http://doi.org/10.1080/03007995.2016.1218839

3. Van Nguyen, N. T. (2019). Combination therapy at the start of hypertension treatment: pros and cons. E-Journal of Cardiology Practice, 17 (20). Available at: https://www.escardio.org/Journals/E-Journal-of-Cardiology-Practice/Volume-17/combination-therapy-at-thestart-of-hypertension-treatment-pros-and-cons

4. Kalra, S., Kalra, B., Agrawal, N. (2010). Combination therapy in hypertension: An update. Diabetology \& Metabolic Syndrome, 2 (1). doi: http://doi.org/10.1186/1758-5996-2-44

5. Wedian, F., Lataifeh, A. (2013). Application of the Bivariate Calibration for Simultaneous Determinations of Hydrochlorothiazide/Enalapril Maleate and Hydrochlorothiazide/Bisoprolol Fumarate in Drug Tablets. International Journal of Chemistry, 5 (2). doi: http://doi.org/10.5539/ijc.v5n2p29

6. Borghi, C., Soldati, M., Bragagni, A., Cicero, A. F. . (2020). Safety implications of combining ACE inhibitors with thiazides for the treatment of hypertensive patients. Expert Opinion on Drug Safety, 19(12), 1577-1583. doi: http://doi.org/10.1080/14740338.2020.1836151

7. Novytska, A. V., Korost, Ya. V., Siryk, V. O. (2017). Kombinovana terapiia arterialnoi hipertenzii: vybir naikrashchoho variantu. Liky Ukrainy, 5 (211), 22-25.

8. Burnier, M., Bakris, G., Williams, B. (2019). Redefining diuretics use in hypertension. Journal of Hypertension, 37 (8), 1574-1586. doi: http://doi.org/10.1097/hjh.0000000000002088

9. ENALAPRIL-H/NL-ZDOROVYE. Kompendium. Lekarstvennye sredstva. Available at: https://compendium.com.ua/ info/168310/enalapril-h-zdorov_e/

10. Derzhavnyi reiestr likarskykh zasobiv Ukrainy. Available at: http://www.drlz.com.ua/

11. The United States Pharmacopoeia, 41 - NF 36 (2018). The United States Pharmacopeial Convention. Rockville. Available at: https://opac.kku.ac.th/catalog/BibItem.aspx?BibID=b00420302 
12. Koppala, S., Ranga Reddy, V., Anireddy, J. S. (2017). User-Friendly HPLC Method Development and Validation for Determination of Enalapril Maleate and Its Impurities in Enalapril Tablets. Journal of Chromatographic Science, 55 (10), 979-988. doi: http://doi.org/10.1093/chromsci/bmx060

13. Abdelrahman, M. M. (2014). Selective spectrophotometric methods for determination of ternary mixture with overlapping spectra: A comparative study. Spectrochimica Acta Part A: Molecular and Biomolecular Spectroscopy, 124, $389-396$. doi: http://doi.org/10.1016/j.saa.2014.01.020

14. Leontiev, D. A., Volovyk, N. V., Bevz, O. V., Vashchenko, O. V., Gryzodub, O. I. (2018). Characterization of a reference standard for qualification of differential scanning calorimetry intended for purity determination in certification of pharmaceutical reference standards. Journal of Pharmaceutical Sciences and Research, 10 (11), 2709-2714.

15. Hammouda, M. E. A., Abu El-Enin, M. A., El-Sherbiny, D. T., El-Wasseef, D. R., El-Ashry, S. M. (2014). Simultaneous Determination of Enalapril and Hydrochlorothiazide in Pharmaceutical Preparations Using Microemulsion Liquid Chromatography. Journal of Chromatographic Science, 53 (1), 90-96. doi: http://doi.org/10.1093/chromsci/bmu024

16. Uslu, B., Özden, T. (2013). HPLC and UPLC Methods for the Simultaneous Determination of Enalapril and Hydrochlorothiazide in Pharmaceutical Dosage Forms. Chromatographia, 76 (21-22), 1487-1494. doi: http://doi.org/10.1007/s10337-013-2442-6

17. Balkanov, T., Logoyda, L., Piponski, M. (2021). Development and validation of a fast and simple HPLC method for the simultaneous determination of bisoprolol and enalapril in dosage form. Pharmacia, 68 (1), 69-77. doi: http://doi.org/10.3897/pharmacia.68.50919

18. British Pharmacopoeia (2020). Available at: https://www.pharmacopoeia.com/

19. Komarytskyy, I. L., Khanin, V. A., Bevz, N. Y., Georgiyants, V. A. (2015). Verification of HPLC method for quantitative determination of amlodipine besylate in tablets. Russian Journal of Biopharmaceuticals, 7 (2), 17-20.

20. Derzhavna Farmakopeia Ukrainy. Vol. 1 (2015). Kharkiv: Derzhavne pidpryiemstvo «Ukrainskyi naukovyi farmakopeinyi tsentr yakosti likarskykh zasobiv»», 1128.

21. The European Pharmacopoeia (2018). European Directorate for the Quality of Medicines \& HealthCare of the Council of Europe. Strasbourg, 6.

22. Derzhavna Farmakopeia Ukrainy (2020). Kharkiv: Derzhavne pidpryiemstvo «Ukrainskyi naukovyi farmakopeinyi tsentr yakosti likarskykh zasobiv», 600 .

Received date 12.01.2021

Accepted date 18.02.2021

Published date 28.02.2021

Nataliia Bevz, PhD, Associate Professor, Department of Pharmaceutical Chemistry, National University of Pharmacy, Pushkinska str., 53, Kharkiv, Ukraine, 61002

E-mail: nata.bevz.60@gmail.com

Artem Myhal, PhD, Engineer, API Synthesis laboratory, Department of Research and Development, JSC "Farmak", Kyrylivska str., 63, Kyiv, Ukraine, 04080

E-mail: artem.migal@gmail.com

Liudas Ivanauskas, Doctor of Biomedical Sciences, Professor, Head of Department, Department of Analytical and Toxicological Chemistry, Lithuanian University of Health Sciences, Mickevičiaus g. 9, Kaunas, Lithuania, LT 44307

E-mail: liudasivn@gmail.com

Olga Gorokhova, PhD, Associate Professor, Department of Pharmaceutical Chemistry,National University of Pharmacy, Pushkinska str., 53, Kharkiv, Ukraine, 61002

E-mail: gorokhova1263@gmail.com

Vasyl Grynenko, PhD, Associate Professor, Department of Pharmaceutical Chemistry, National University of Pharmacy, Pushkinska str., 53, Kharkiv, Ukraine, 61002

E-mail: grynenko77@gmail.com

Iryna Zhuravel, Doctor of Chemical Sciences, Professor, Department of Clinical Biochemistry, Forensic Toxicology and Pharmacy, Kharkiv Medical Academy of Postgraduate Education, Amosova str., 58, Kharkiv, Ukraine, 61176

E-mail: Irina.tox@gmail.com 